\title{
Shrinkage, Weight Loss and Crack Prevention During Binder Burn Out of Components Produced by Fused Deposition of Ceramics (FDC)
}

P. Bhargava, A. Bandyopadhyay, S. Rangarajan, G. Qi, C. Dai, S. Wu, S. Danforth and A. Safari Department of Ceramic and Materials Engineering, Rutgers University, Piscataway, NJ 08855

\begin{abstract}
In the present study the sequential stages of the previously established binder burn out (BBO) route were characterized by obtaining precise shrinkage and weight loss measurements from interrupted runs. A DoE (Design of Experiments) approach was adopted to systematically investigate the effect of process variables; such as the heating rates during critical segments, part dimensions and environment (flowing nitrogen vs vacuum) on the shrinkage, weight loss and cracking during binder burn out. A stepwise TGA was performed to study the effect of ramp rate and dwell time on the kinetics of binder burn out, and an experiment was conducted to determine optimum wicking conditions. The results from this study have been used to maximize the weight loss and minimize the cracking during binder burn out cycle for FDC parts with different sizes.
\end{abstract}

1. Introduction: Fused deposition of ceramics (FDC) is a very efficient near net shape processing technique to produce functional ceramic components with highly complex geometries without the use of any part specific tooling, dies or molds. The other key advantages of this process include rapid and cost effective iterative design optimization and small batch production of complex, high value parts. Among the different steps involved in FDC of functional ceramic components, binder removal is critical to producing defect free sintered parts with functional quality.

In the present study, binder removal is done by burning out the binder in two stages. In the first stage (Fig. 1), the majority of the binder is burned out in the presence of high purity flowing nitrogen. The residual binder after stage I is burned out in air during stage II of the process. The binder burn out (BBO) behavior is affected by a large number of variables including: (a) material specific variables such as - ceramic particle size distribution and surface area of the powder, ceramic volume fraction, ceramic powder agglomeration, binder composition, binder volume fraction, and the nature of powder bed, (b) process specific variables such as - binder distribution within the green part (as in extrusion or different FDC build patterns), heating rate, dwell temperature and times, furnace environmental conditions, the flow rate or partial pressure of gases (air, inert or vacuum), and (c) part specific variables such as - part size, geometry, surface area to volume ratio, FDC build orientation, preexisting porosity in the FDC part or other defects.

Previous work at Rutgers established a working heating schedule for BBO of FDC components up to 0.5 " x 0.5 " cross-sectional area (Fig. 1) [1]. In the first step of this BBO cycle, nearly $80 \%$ of the binder is removed from the green body and the residual binder is removed using a static air cycle up to $450^{\circ} \mathrm{C}$. The objectives of this study were: (a) to examine the sequential binder weight loss and the associated shrinkage at different temperatures of the BBO cycle, (b) to use a Design of Experiments (DoE) approach to identify the critical variables in the binder burn out process and their effects, (c) gain some insight into the mechanisms of BBO process that lead to shrinkage and cracking of parts, and (d) to optimize the existing BBO cycle to obtain defect free parts.

2. Experimental: Samples for this study were produced via FDC and single screw extrusion techniques with RU9 thermoplastic binder loaded with 55 volume \% GS-44 silicon nitride powder [2]. Oleyl alcohol was used as a dispersant. The RU9 binder is composed of four components -a 
polymer that acts as a backbone, an elastomer that imparts flexibility, a tackifier that promotes adhesion between roads during FDC, and a wax component that modulates the viscosity of the binder system.

Samples were ground in the green state using 120,320,600 grit $\mathrm{SiC}$ paper to obtain a smooth surface finish. Samples were weighed and the dimensions were carefully measured at the center of the opposing sample faces using a high precision micrometer. Interrupted binder burn out experiments were carried out with extruded samples with dimensions $-1.27 \mathrm{~cm} \mathrm{x} 1.27 \mathrm{~cm} \mathrm{X} 1.27 \mathrm{~cm}$. For the Design of Experiments (DoE) and other controlled studies, FDC samples with either $-1.6 \mathrm{~cm}$ $\times 1.6 \mathrm{~cm}$ or $2.5 \mathrm{~cm} \times 2.5 \mathrm{~cm}$ cross-sectional area with $1.27 \mathrm{~cm}$ along the thickness direction were used. The thickness dimension was also the build direction duirng FDC. The present study involved only the stage I of the BBO cycle since about $80 \%$ of the binder removal occurs in this stage. Moreover, most of the cracking is most likely to occur during stage I of the BBO cycle [1]. For the interrupted runs, 3 extruded samples per temperature and time were used. For the DoE and other studies, 1 FDC sample per experiment was used. For at least one FDC sample per DoE condition, shrinkage along the build direction $(\mathrm{z})$ was measured at the face center and also near the edges.

2.1 Interrupted binder burn out: The baseline BBO cycle, developed earlier for parts with $1.27 \mathrm{~cm} \mathrm{x}$ $1.27 \mathrm{~cm}$ cross-section was used (Fig. 1). Samples were heated up to selected temperatures, and after a 5 hour dwell time, the samples were furnace cooled to room temperature.

2.2 Design of Experiments (DoE): The DoE approach was initiated with the objectives of: (1) developing a model that can predict optimum BBO conditions, (2) identifying the most critical variable among the selected experimental variables and (3) determining if binder removal from larger cross-section parts can be carried out using the existing or modified cycle without generating any defects [3].

Based on historical data [1], the following factors were identified as the most critical experimental variables during $\mathrm{BBO}$. For each of the variables the low and high values used in the DoE are also shown -

(1) Ramp rate $\left(\mathbf{r}_{1}\right)$ for the segment $80^{\circ} \mathrm{C}$ to $150^{\circ} \mathrm{C}$, with low and high values -4 and $10^{\circ} \mathrm{C} / \mathrm{h}$.

(2) Ramp rate $\left(\mathbf{r}_{2}\right)$ for the segment $150^{\circ} \mathrm{C}$ to $300^{\circ} \mathrm{C}$, with low and high values -2 and $10^{\circ} \mathrm{C} / \mathrm{h}$

(3) Cross-section (x-sect) of the samples, with low and high values $-2.56 \mathrm{~cm}^{2}$ and $6.25 \mathrm{~cm}^{2}$.

(4) Environment (env) following the $5 \mathrm{hr}$ hold at $200^{\circ} \mathrm{C}$ - flowing $\mathrm{N}_{2}$ and vacuum.

The design matrix is shown in Table I. The low and high values for each of the factors were purposefully chosen such that significant changes in the measured response could be produced. Specifically, the lower values of the ramp rate were chosen based on the historical data for successful $\mathrm{BBO}$ runs. From the previously available data on $\mathrm{Hg}$ porosimetry, it was known that generation of interconnected porosity in the FDC samples starts around $200^{\circ} \mathrm{C}$. Thus, in the DoE, condition involving the use of vacuum was implemented after a 5 hour hold at $200^{\circ} \mathrm{C}$.

The following conditions were fixed during the DoE: heating rates except $r_{1}$ and $r_{2}$; dwell times for all the soak segments; peak temperature of each of the BBO segments; point of initiation of vacuum during $\mathrm{BBO}$; placement of samples with respect to their build orientation during FDC; handtooling procedure; embedding of the part in the activated carbon setter powder.

The measures of response for the process were: (1) shrinkage along $\mathrm{x}, \mathrm{y}$ and $\mathrm{z}$ (FDC build direction), (2) part cracking as determined by visual inspection, (3) binder weight loss, and (4) difference in $z$ shrinkage from center to the edge of the sample on the $x-y$ face. DoE KISS (Air Academy Associates, Colorado Springs, CO) software was used to analyze the experimental data. 
TABLE I: DoE Design Matrix and the Corresponding Measures of Response:

\begin{tabular}{|c|c|c|c|c|c|c|c|c|c|c|}
\hline $\begin{array}{l}\text { Run } \\
\#\end{array}$ & $\begin{array}{l}\mathbf{r}_{1} \\
\left({ }^{\circ} \mathrm{C} / \mathrm{hr}\right)\end{array}$ & $\begin{array}{l}\mathbf{r}_{2} \\
\left({ }^{\circ} \mathrm{C} / \mathrm{hr}\right)\end{array}$ & $\begin{array}{l}\text { X-sect } \\
\left(\text { inch }^{2}\right)\end{array}$ & $\mathrm{env}^{+}$ & $\begin{array}{l}\Delta \mathrm{x} \\
(\%)^{*}\end{array}$ & $\begin{array}{l}\Delta \mathrm{y} \\
(\%)^{*}\end{array}$ & $\begin{array}{l}\mathrm{z} \\
(\%)^{*}\end{array}$ & \begin{tabular}{|l|} 
Crack/ \\
Delamination
\end{tabular} & $\begin{array}{l}\text { Gradient } \\
\text { in } \Delta \mathrm{z}^{\phi} \\
\text { (\%/inch) }\end{array}$ & $\begin{array}{l}\Delta \mathrm{wt} . \\
(\%)\end{array}$ \\
\hline 1 & 4 & 2 & 0.4 & 1 & $\begin{array}{l}-1.04 \\
-0.87 \\
\end{array}$ & \begin{tabular}{|l|}
-0.99 \\
-0.89 \\
\end{tabular} & \begin{tabular}{|l|}
-0.93 \\
-1.24 \\
\end{tabular} & $\begin{array}{l}\text { No } \\
\text { No }\end{array}$ & 0.2 & $\begin{array}{c}94.6 \\
94 \\
\end{array}$ \\
\hline 2 & 4 & 2 & 1 & 1 & $\begin{array}{l}-0.31 \\
-0.72 \\
\end{array}$ & \begin{tabular}{|l|}
-0.76 \\
-0.76 \\
\end{tabular} & \begin{tabular}{|l|}
-0.81 \\
-0.60 \\
\end{tabular} & $\begin{array}{l}\text { No } \\
\text { No }\end{array}$ & -0.41 & $\begin{array}{l}96 \\
92 \\
\end{array}$ \\
\hline 3 & 4 & 10 & 0.4 & -1 & $\begin{array}{l}-0.83 \\
-0.62\end{array}$ & $\begin{array}{l}-0.86 \\
-0.62\end{array}$ & $\begin{array}{l}-0.70 \\
-0.62\end{array}$ & $\begin{array}{l}\text { Yes } \\
\text { Yes }\end{array}$ & 0.05 & $\begin{array}{l}>99 \\
>99\end{array}$ \\
\hline 4 & 4 & 10 & 1 & -1 & $\begin{array}{l}-0.63 \\
-0.67\end{array}$ & $\begin{array}{l}-0.80 \\
-0.72\end{array}$ & $\begin{array}{l}0.78 \\
0.58\end{array}$ & $\begin{array}{l}\text { Yes } \\
\text { Yes }\end{array}$ & -1.16 & $\begin{array}{l}>99 \\
>99\end{array}$ \\
\hline 5 & 10 & 2 & 0.4 & -1 & $\begin{array}{r}-0.73 \\
-0.79 \\
\end{array}$ & $\begin{array}{r}-0.88 \\
-0.78 \\
\end{array}$ & $\begin{array}{c}-0.64 \\
-0.9\end{array}$ & $\begin{array}{l}\text { No } \\
\text { No } \\
\end{array}$ & 0 & $\begin{array}{r}>99 \\
>99 \\
\end{array}$ \\
\hline 6 & 10 & 2 & 1 & -1 & $\begin{array}{l}-0.65 \\
-0.74 \\
\end{array}$ & \begin{tabular}{|l|}
-0.71 \\
-0.44 \\
\end{tabular} & \begin{tabular}{|l|}
1.27 \\
0.44 \\
\end{tabular} & $\begin{array}{l}\text { Yes } \\
\text { Yes }\end{array}$ & -1.02 & $\begin{array}{r}>99 \\
>99 \\
\end{array}$ \\
\hline 7 & 10 & 10 & 0.4 & 1 & $\begin{array}{l}-0.85 \\
-0.58 \\
\end{array}$ & \begin{tabular}{|l|}
-0.84 \\
-0.75 \\
\end{tabular} & $\begin{array}{c}-0.32 \\
0.27 \\
\end{array}$ & $\begin{array}{l}\text { Yes } \\
\text { Yes }\end{array}$ & 0.15 & $\begin{array}{c}>99 \\
92\end{array}$ \\
\hline 8 & 10 & 10 & 1 & 1 & $\begin{array}{r}-0.41 \\
-0.52 \\
\end{array}$ & $\begin{array}{l}-0.35 \\
-0.56 \\
\end{array}$ & $\begin{array}{l}1.5 \\
1.8 \\
\end{array}$ & $\begin{array}{l}\text { Yes } \\
\text { Yes }\end{array}$ & -1.88 & $\begin{array}{c}94.8 \\
91 \\
\end{array}$ \\
\hline
\end{tabular}

* negative values imply shrinkage and positive imply an expansion; + Here 1 represents $\mathrm{N}_{2}$ and -1 represents vacuum; $\phi$ This is computed as the difference between measured shrinkage at the edge and center of the face divided by the half width of the sample, thus negative value implies greater shrinkage at the edge.

2.3 Thermomechanical (TMA) and thermogravimetric (TGA) analysis: A TMA (Perkin-Elmer) was used to measure the thermal expansion of the RU9 binder from room temperature to $70^{\circ} \mathrm{C}$. The thermal expansion of RU9 was found to be $147 \times 10^{-6} /{ }^{\circ} \mathrm{C}$, much larger than the $3.2 \times 10^{-6} /{ }^{\circ} \mathrm{C}$ for the $\mathrm{Si}_{3} \mathrm{~N}_{4}$ used. A TGA was performed to determine the effects of heating rate and dwell time on the kinetics of weight loss in different temperature regimes. A RU955 sample fabricated by FDC was used for the TGA run. The results obtained are shown in Figure 2.

\section{Results and Discussion}

3.1 Interrupted binder burn out: The results from interrupted BBO tests are shown in Figure 3. The data obtained in these studies was compared to the previous data [1] on binder weight loss measured for samples air quenched from the temperatures considered. At $150^{\circ} \mathrm{C}$, the binder weight loss increased from $4 \%$ for quenched samples to $10 \%$ for samples with a 5 hours hold. In contrast a 5 hour hold at $350^{\circ} \mathrm{C}$ did not lead to significant increase in the binder weight loss as compared to that obtained with no hold. Thus, at higher temperatures, the sample equilibrates with the surrounding environment in a much shorter time as compared to that at lower temperatures.

TGA analysis (Fig. 2) showed very little binder weight loss ( $\leq 2.5 \%)$ until the temperature exceeded $190^{\circ} \mathrm{C}$. Thus the weight loss at $150^{\circ} \mathrm{C}(\sim 10 \%)$ must have been due to the flow of liquid binder via capillarity into the surrounding bed of activated carbon powder [4]. This outward flow of binder enhanced by the presence of powder bed, in this case activated carbon, is termed wicking. The loss of binder by wicking induces particle rearrangement leading to particle compaction and thus 
shrinkage in sample dimensions [5]. The largest shrinkage was obtained in the segment $80^{\circ} \mathrm{C}$ to $150^{\circ} \mathrm{C}$ (Fig. 3(b)). The measured shrinkage in part dimensions decreased with increase in temperature but this does not imply an increase in particle separation. The observed decrease in shrinkage is most likely due to the fact that when the part is cooled from higher temperatures it has lost more of the high thermal expansion phase, i.e. the binder [6].

3.2 Design of Experiments : A half factorial design matrix was used in this study. The design included 4 factors with 8 runs, and for each of the runs two iterations were performed. The design matrix and the corresponding results for the different measures of response are shown in Table 1. The run \#1 represents the baseline BBO cycle that was previously developed at Rutgers for 0.5 " $\mathrm{x}$ 0.5 " cross-sectional parts. The complete baseline BBO cycle is shown in Fig.1. All the other conditions represent changes in the four variables incorporated into the baseline cycle.

The importance of the variables considered in this study can be understood by analyzing the step by step changes that occur during binder burn out of the FDC parts. As a part is heated, the binder begins to soften and expand causing the ceramic particles to move farther apart. With further increase in temperature, the viscosity of the binder system decreases allowing it to flow out of the part into the surrounding powder bed due to capillary forces. The capillary forces applied by the binder as it wicks out cause particle compaction that leads to shrinkage in part dimensions. As seen through weight loss and shrinkage (section 3.1) measurements, this mechanism is dominant at temperatures near $150^{\circ} \mathrm{C}$. Since particle rearrangement occurs in this low temperature regime $(\mathrm{T}<$ $150^{\circ} \mathrm{C}$ ), the heating rate $r_{1}$ can influence the final shrinkage percentage. During the low temperature regime, the two opposing processes in terms of particle packing that occur are the large thermal expansion of the binder that causes particles to move apart and the outward flow of binder at slightly higher temperature that cause particle compaction. When very high heating rates $\left(r_{1}\right)$ are used, the particles that moved away due to expansion may not get compacted due to insufficient time for the binder to flow out especially in larger cross-section samples unless compensated for by longer hold times at appropriate temperature (see section 3.3). High values of $r_{1}$ can also cause cracking due to non-uniform heating of the sample cross-section. In the present $\mathrm{DoE}$ even though the sample size has been considered as a variable, the dwell time has not been considered as a variable.

Heating to higher temperatures $\left(\mathrm{T}>185^{\circ} \mathrm{C}\right)$ initiates loss of binder by decomposition/evaporation mechanism (Fig.3). For $0.5^{\prime \prime} \times 0.5^{\prime \prime}$ RU955 parts, porosity formation starts from $200^{\circ} \mathrm{C}$ [1]. Thus heating above $200^{\circ} \mathrm{C}$ will lead to a reduction in the diffusion path for escape of the binder from the dimensions of sample to the scale of the microstructure. It is notable that under the same environmental conditions as used for the 0.5 " $\times 0.5$ " cross-sectional area parts, evolution of the pore structure in larger parts will require a different heating schedule due to the greater amount of binder that needs to be removed. For larger samples, heating at faster rates $\left(r_{2}\right)$ for $\mathrm{T}>150^{\circ} \mathrm{C}$ will result in less time for formation of interconnected porosity, leading to a build up of vapor pressure within the sample due to rapid decomposition. The build up of vapor pressure within the sample can only be prevented if the removal rates match or exceed the vapor generation rate. Usually the high vapor pressure within the sample can cause formation of delamination/cracks. For the situation described above, if vacuum is used before the interconnected porosity has developed, the large gradient created between the inside of the sample (positive vapor pressure) and the vacuum (outside the sample) will promote the formation of delamination/cracks parallel to the build layers.

Analysis of the data presented in Table $\mathrm{I}$ indicates that the shrinkage along $\mathrm{x}$ and $\mathrm{y}$ direction was significantly affected by an increase in sample dimensions but was insensitive to changes in heating rates (Fig. 4(a)) or the environment. In contrast, the shrinkage along $z$ (Fig.4 (b)) or the 
build direction was significantly affected by all the variables - heating rates during low and high temperature regimes, part cross-section area and environment - but among them, the cross-section area exhibited the strongest influence. This difference is related to the binder distribution in the FDC samples. As shown by a previous study [1], a greater concentration of the binder exists in between the build layers (normal to the build direction). Thus, for the samples in this study (with $\mathrm{z}$ as the FDC build direction), the shrinkage after complete binder removal should be greater in $z$ direction than in the $\mathrm{x}$ or $\mathrm{y}$ directions. For most of the DoE runs, measured shrinkage in the $\mathrm{z}$ direction was less than in $\mathrm{x}$ or $\mathrm{y}$ directions except for run \#1 which is the cycle developed previously at Rutgers

The DoE analysis predicted that the part cracking tendency is most strongly influenced by changes in ramp rate during the high temperature regime specifically between $150-300^{\circ} \mathrm{C}$. Most of the delamination cracks observed in this study were perpendicular to the FDC build direction. The use of vacuum had only a slight influence on the part cracking tendency.

The gradient in shrinkage along $z$ (measured on the $x-y$ face) from face center to the edge is a measure of the extent of porosity developed within the sample before significant weight loss begins to occur by decomposition/evaporation. Analysis of the measured data indicated that the gradient in shrinkage was most strongly influenced by the size of the samples. For smaller samples the shrinkage in $\mathrm{z}$ (build direction) was greater at the face center than at the edge, while for the larger samples (1" $\mathrm{x} 1$ " cross-sectional area) the measured shrinkage was always greater at the sample edges than at the face center, regardless of the environment used $\left(\mathrm{N}_{2}\right.$ or vacuum ) (see Table 1). In general, the magnitude of this difference between shrinkage at the face center and the edge was greater for larger cross-section samples. This implies that for the larger samples, the binder could not be removed very uniformly from the whole volume of the sample possibly due to a lack of well-connected path for binder removal throughout the sample. The gradient in shrinkage along $\mathrm{z}$ from center to the edge of the sample was smallest for the condition with the lowest ramp rates (condition 2 in Table 1).

There are few studies [7] reported in the literature on the use of vacuum to enhance binder removal for larger size parts. In the present study, vacuum was used to investigate the removal of binder from large samples and to investigate the relationships between the use of vacuum and different heating rates. For the purpose of matching the rates of generation of vapors from the binder and their removal, vacuum should not be applied along with the use of high heating rates. Comparing conditions 3 and 5 (Table 1) it can be seen that the use of high ramp rate coupled with the use of vacuum (run \# 3) leads to cracking, while a lower ramp rate $\left(r_{2}=2^{\circ} \mathrm{C} / \mathrm{hr}\right.$ ) with vacuum (run \#5) did not lead to cracking. The use of vacuum with high heating rates can result in one or more of the following: (1) insufficient time to create adequate porosity leading to a pressure differential between the inside and outside of the sample, (2) binder removal preferentially from the surface causing a gradient in particle packing from outside to inside which leads to residual stresses, (3) excessive vapor generation due to both rapid heating and the driving force due to negative pressure (Le Chatelier's principle). The existence of large pressure differential or residual stresses can lead to defect formation inside or at the surface of the sample.

The initiation of vacuum at low temperatures can also lead to similar effects due to insufficient time for creation of well connected path for binder removal throughout the sample. This is illustrated by conditions 4 and 6 where the larger cross-section samples were used. For smaller samples, the time spent during heating to initiation of vacuum was sufficient as suggested by the uniform measured shrinkage and the absence of any cracks (condition 5). Notice that the heating rates $\left(r_{1}\right.$ and $\left.r_{2}\right)$ were varied in the same range and dwell times were the same for both the small and large size samples used in this study. The former is a requirement to enable comparison among different DoE conditions. From the above discussion it can be concluded that the use of low vacuum 
especially during dwell segments or accompanied by low heating rates may be favorable for enhanced binder removal rates. It is important to apply the vacuum only after generation of interconnected porosity in the sample.

3.3 Stepwise TGA and comparison of wicking at different temperatures: As shown in Fig. 3 it can be seen from the stepwise TGA that any significant weight loss by decomposition/vaporization does not start until about $185^{\circ} \mathrm{C}$. The dwell segments at higher temperatures also show a higher weight loss rate than those at low temperatures. Thus larger samples should be subjected to longer dwell times (at higher temperatures) to achieve equilibrium weight loss before increasing the temperature further. The weight loss rate and thus the rate of vapor generation increased significantly above $300^{\circ} \mathrm{C}$ suggesting the use of lower ramp rates at high temperatures.

The previously established BBO cycle (Fig. 1) included a dwell at $150^{\circ} \mathrm{C}$ to promote binder loss by wicking. A dwell at a temperature greater than $150^{\circ} \mathrm{C}$ but lower than the temperature at which significant weight loss by vaporization begins can enhance wicking due to lowering of binder viscosity. Since the TGA indicated that significant weight loss by vaporization begins around $185^{\circ} \mathrm{C}$, an experiment was conducted to examine the effects due to wicking at higher temperature $(\mathrm{T}<$ $185^{\circ} \mathrm{C}$ ). The following two conditions were chosen for comparison $-150^{\circ} \mathrm{C}$ and $175^{\circ} \mathrm{C}$ with 10 hour dwell times using the smaller size FDC samples $\left(0.63\right.$ " $\times 0.63$ " $\left.\times 0.5^{\prime \prime}\right)$. The weight loss and the associated shrinkages obtained are shown in Table II. The $\mathrm{z}$ shrinkages from center to the edge of the sample were quite uniform. Similar experiments have to be performed to confirm if uniform shrinkage can be obtained at the higher wicking temperature for larger samples.

TABLE II. Comparison of Binder Wicking Conditions and Associated Shrinkage and Weight Loss.

\begin{tabular}{|l|l|l|l|l|}
\hline Interrupted BBO condition & $\Delta \mathrm{x}(\%)$ & $\Delta \mathrm{y}(\%)$ & $\Delta \mathrm{z}(\%)$ & binder weight loss $(\%)$ \\
\hline $150^{\circ} \mathrm{C}, 10$ hours & -1.17 & -1.15 & -1.18 & 8.10 \\
\hline $175^{\circ} \mathrm{C}, 10$ hours & -1.44 & -1.34 & -1.97 & 11.19 \\
\hline
\end{tabular}

From the data presented in Table II above, it can be seen that shrinkage caused by wicking along the $\mathrm{z}$ (FDC build direction) is a strong function of temperature, while shrinkage along $\mathrm{x}$ and $\mathrm{y}$ are somewhat less sensitive to the temperature at which wicking occurs.

Based on all the above results some of the changes to the BBO cycle (Fig. 1) that have been/will be made include - direct ramp up to $80^{\circ} \mathrm{C}$ and a 2 hours dwell; a higher temperature dwell at $175^{\circ} \mathrm{C}$ ( 5 hours) to promote wicking; increase dwell times with increases in sample size; increase the final temperature to $400^{\circ} \mathrm{C}$ ( 5 hours) to decrease the amount of residual binder/carbon to be burned off during the air cycle.

Summary and Conclusions: (1) Significant amount of the particle packing occurs in the low temperature regime when the dominant binder weight loss is due to wicking; (2) Binder removal by wicking at higher temperatures (low viscosity) can lead to greater weight loss and shrinkage; (3) Cracking of parts was found to be most significantly influenced by heating rates; (4) Cracks/delamination always occurred perpendicular to the $\mathrm{z}$ direction and not across the layer; (5) Changes in heating rates had a slight influence on shrinkage along $\mathrm{x}$ and $\mathrm{y}$ directions, but significant influence on shrinkage along $\mathrm{z}$ (build direction); (6) Shrinkage along $\mathrm{x}, \mathrm{y}$ and $\mathrm{z}$ was strongly influenced by changes in the size of the sample; (7) Use of vacuum can prove to be very useful in accelerating binder removal when used at an appropriate stage i.e. when interconnected porosity has formed; (8) Vacuum should preferably be used during hold segments or with lower ramp rates. 
Acknowledgments: The authors acknowledge the financial support from DARPA/ONR (contract no. N00014-94-0115). The authors also acknowledge the discussions and support provided by Mr.R. Clancy, Drs. P. Whalen and V. Jamalabad at Allied Signal, Research and Tech., Morristown, NJ.

References: 1. A. Bandyopadhyay et. al., unpublished research, Rutgers University, 1996.

2. "FDC, Rapid Fabrication of Structural Components," M.K. Agarwala, A. Bandyopadhyay, R. VanWeeren, A. Safari, S.C. Danforth, N.A. Langrana, V.R. Jamalabad, P.J. Whalen, Am. Ceram. Soc. Bull., November 1996, pp. 60-65.

3. Understanding Industrial Designed Experiments, S. R. Schmidt and R.G. Launsby, Ed. By M. J. Kimele, Air Academy Press, Colorado Springs, CO, 1994.

4. G. Bandyopadhyay and K.W. French, "Effects of Powder Characteristics on Injection Molding and Burnout Cracking," Bull. of the Am. Ceram. Soc., Vol. 73, no. 3, pp. 107-114, 1994.

5. "Observation of Poly(Vinyl Butryral)- Dibutyl Phthalate Binder Capillary Migration,"M.J. Cima, M. Dudziak and A.D. Devoe, J. Mater. Sci., 24 [6] 1087-90 (1989).

6. "Shrinkage and Particle Packing during Removal of Organic Vehicle from Ceramic Injection Mouldings," H. M. Shaw and M. J. Edirisinghe, J. Eur. Ceram. Soc., 13, 135-142, (1994).

7. "Binder Removal from Injection Moulded Ceramic Turbocharger Rotors," E. Carlstrom, M. Sjostedt, B. Mattsson and L. Hermansson, Sc. of Ceram., Ed. By Derek Taylor, 14, p. 199, 1988.

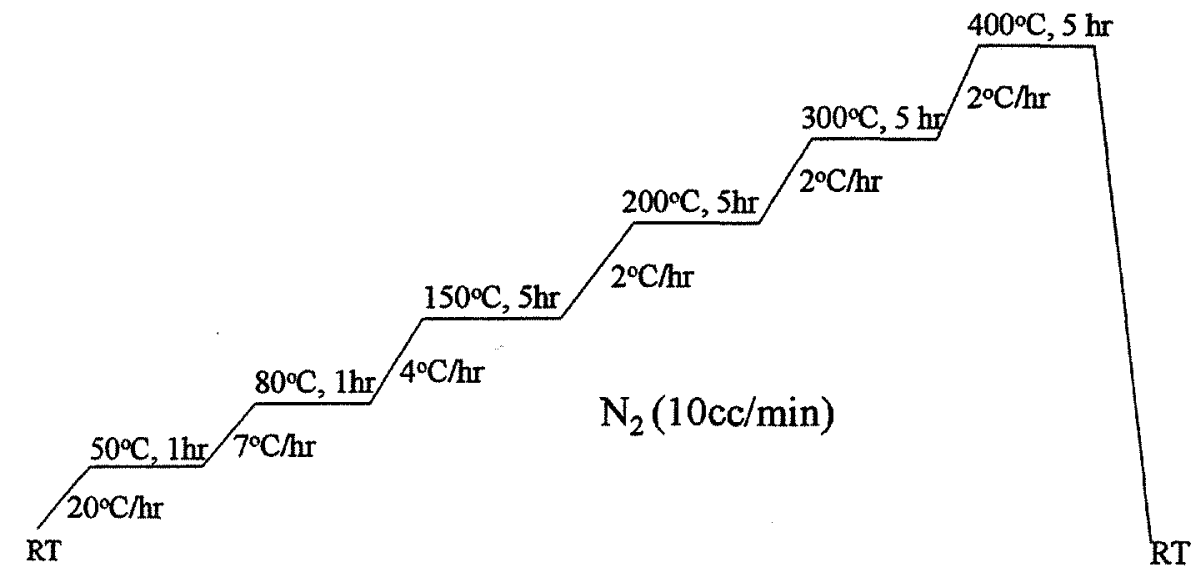

Fig.1 Previously developed binder burn out heating schedule for $1.27 \mathrm{~cm} \times 1.27 \mathrm{~cm}$ cross-section area FDC parts.

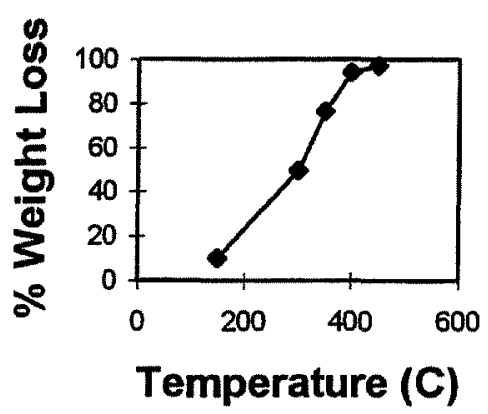

(a)

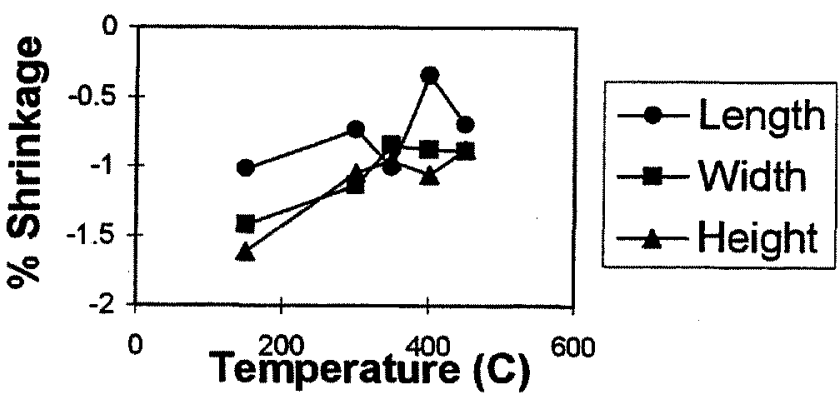

(b)

Fig. 3 (a) Binder weight loss and (b) percentage shrinkage in green dimensions following a 5 hour hold at the temperatures of interrupted binder burn out. 


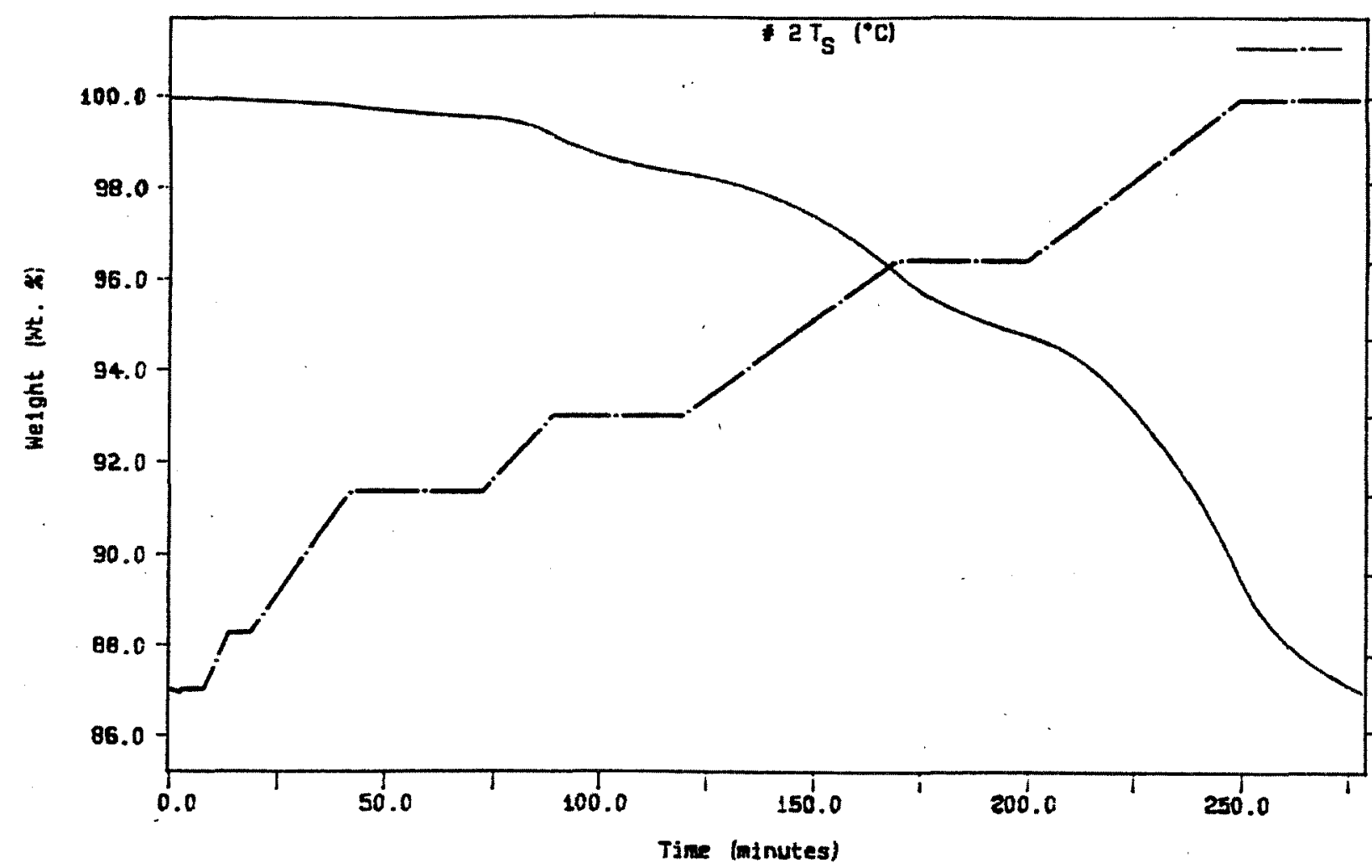

400.0

350.0

$300.0 \div$

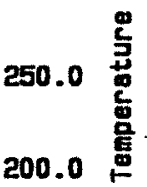

150.0

100.0

50.0

0.0

Fig. 2 TGA analysis of RU955 sample produced by FDC.

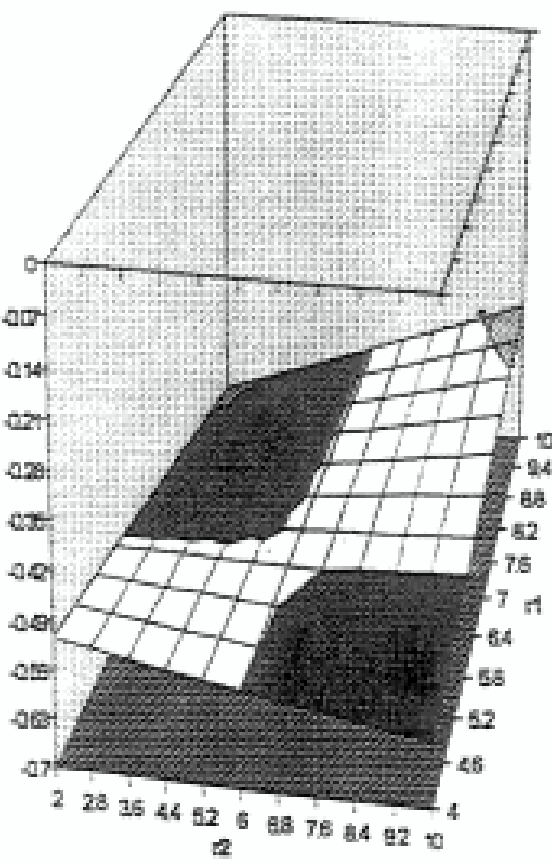

(a)

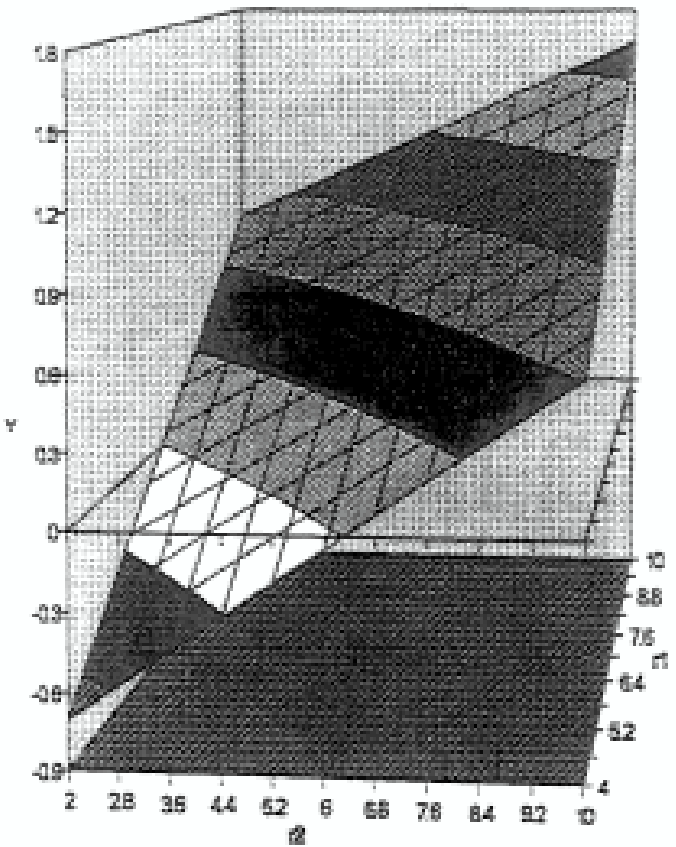

(b)

Fig.4 Shrinkage along (a) $x$ and (b) $z$ as a function of the two heating rates $r_{1}$ and $r_{2}$. 